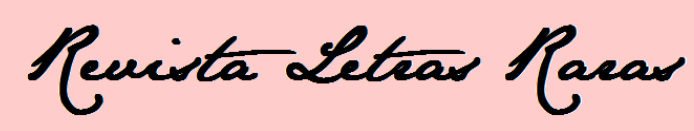

ISSN: 2317-2347 - v.6, n.1 (2017)

\title{
Entrevista com a presidente do Programa Idiomas sem Fronteiras, Denise Martins de Abreu-e-Lima
}

Entendendo a importância do Programa IsF, a Revista Letras Raras interpelou a presidente do Programa que, gentilmente, concedeu esta entrevista ${ }^{i}$ :

RLR: Considerando o objetivo do Programa IsF como caminho para a internacionalização do Brasil, que avaliação você faz do impacto do Programa.

O Programa Idiomas sem Fronteiras já nasceu de uma perspectiva voltada para o fortalecimento da internacionalização no Brasil, como auxílio ao Ciências sem Fronteiras. Mas, ao longo deste processo nesses últimos 4 anos, ele foi se mostrando mais do que estruturante para as universidades, nesse processo da internacionalização. [Por que mais que estruturante?] Porque ele se organiza em duas grandes frentes: uma frente, obviamente, da formação para profissionais da Língua Estrangeira (LE); prepará-los para esse processo da internacionalização, que é algo que não é foco dos cursos de Letras; em geral, eles formam professores para a Educação Básica e, obviamente, com a formação desses novos profissionais e a residência docente incluída no Programa, a gente está atendendo a comunidade universitária para atingir as metas da internacionalização que a instituição deseja.

Neste processo de recredenciamento, após 4 anos de Programa, nós recredenciamos 58 Universidades Federais e passamos a credenciar 21 Universidades Estaduais e uma Municipal. Isso significa que, hoje, temos no Programa 80 universidades, que estão de acordo com a estrutura e com os objetivos e metas do Programa. Para esse recredenciamento, uma das solicitações feitas às instituições foi a elaboração de uma política linguística que desse suporte e institucionalizasse não somente as ações dos NUCLIs, das universidades, como também dos centros de línguas que as universidades têm. Ou seja, existe uma necessidade de a universidade reconhecer as ações que a gente investe no Programa, tais como a aplicação de testes de nivelamento, de proficiência, os cursos presenciais, a distância ou híbridos.

Assim, a nossa intenção é o processo de alavancagem de reconhecimento da importância de se estudar LE, dentro da instituição. Um professor, um profissional, um aluno 


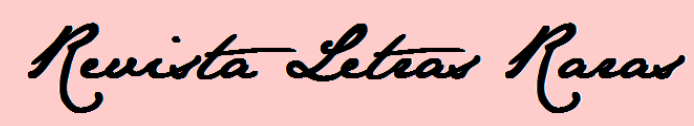

ISSN: 2317-2347 - v.6, n.1 (2017)

de graduação e/ou pós-graduação, que queira realmente fazer uma articulação internacional, precisa ter conhecimento de línguas e a política linguística institucional pode não só reconhecer, como fortalecer todos esses processos.

Dessa forma, como eu avalio o impacto? Eu acho que nunca se falou tanto sobre política linguística neste país, como está sendo falado agora, por conta do Programa Idiomas sem Fronteiras (IsF). São 80 universidades discutindo a sua política institucional e isso já tem refletido inclusive no exterior. Muitos outros países estão querendo saber, a exemplo do México, dos Estados Unidos, do Canadá, da França, da Inglaterra, da Itália, todos querendo saber exatamente o que o Brasil vem fazendo com esse foco da internacionalização e como está conseguindo investir nessas políticas linguísticas. Então, o Estado está fazendo o seu papel de fomentar essa discussão e articulação, respeitando a autonomia universitária para que ela mesma decida qual é a sua motivação, qual é a sua necessidade e de que forma ela vai implementar essas ações.

RLR: Então, pode-se dizer que o IsF mudou o panorama e a valorização das LE no Brasil?

Sim. Eu acredito que sim. No Programa, nós contamos com a participação de muitos especialistas. Acho que nunca foi dada tanta valorização para os especialistas de Línguas Estrangeiras, simultaneamente. Lógico que existem Programas mesmo dentro da universidade, muitos fazem um trabalho primoroso; mas, de forma conjunta, coletiva, organizada, essa é a primeira vez que a gente vê isso no Brasil. Pelo Programa IsF, por exemplo, já passaram mais de 200 (duzentos) especialistas da área de Língua Inglesa, no Programa, sendo bolsistas do Programa e mais de 800 (oitocentos) alunos de graduação que também como bolsistas do Programa, alunos de graduação de licenciatura em inglês para participar do nosso processo formativo.

E o que vale mencionar é que a valorização desse profissional não é só pela visibilidade do trabalho que vem fazendo; mas, pela dedicação. O bolsista tem $20 \mathrm{~h}$ para se dedicar ao programa... ele aprende de tudo, desde o processo de gestão, de organização dos cursos, da submissão de cursos, o acompanhamento. Ele tem que ter letramento digital para lidar com diferentes sistemas do IsF; ele tem também que conhecer e articular com os parceiros internacionais; enfim, trabalhar com a comunidade universitária, ser respeitado pela comunidade universitária que afinal de contas, nesse processo formativo, ele está auxiliando a 


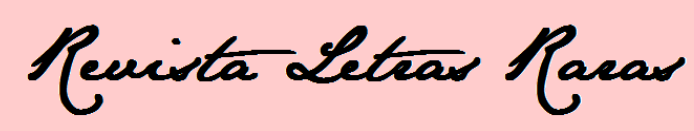

ISSN: 2317-2347 - v.6, n.1 (2017)

a ter a sua proficiência em LE...é um processo de win-win game, todo mundo sai ganhando e acabamos sendo valorizado pelo trabalho que realizamos.

\section{Para chegar até aqui, quais foram os principais obstáculos a serem superados?}

Os principais obstáculos para a implementação de um Programa desse porte foram também as questões que nos motivaram a achar soluções para eles. Por exemplo, o Brasil é imenso, um país continental, cheio de diferenças regionais, cada universidade com as suas necessidades, com a sua estrutura e, obviamente, os especialistas com pontos de vista às vezes muito distintos um do outro. Então, um dos obstáculos é justamente essa diversidade; mas, ao mesmo tempo, é o que mais nos torna únicos, é o fato de valorizar essa diversidade e procurar atendê-la. Eu acredito que o maior obstáculo é a gente planejar, de forma estruturante, com todas essas universidades, tendo um objetivo comum.

E assim, pra a gente conseguir articular isso nos diferentes locais, sobre a mesma perspectiva, tivemos que construir um sistema de gestão que desse conta de toda essa diversidade. Ele ainda está em processo de melhorias, mas é um sistema robusto que permite fazer articulação de todas as ações do Programa. Mas, isso por si só já constitui vários desafios, porque como um sistema pode dar conta dessas diversidades[?]... nós estamos em processo de construção e articulação, o tempo todo. Eu falo que a gente está num Programa em constante construção, é o mesmo que dizer que a gente anda num carro que está sendo construído... esse é um primeiro grande obstáculo que eu acredito que estamos ultrapassando: a formação de uma rede sólida entre os especialistas destruindo essas fronteiras entre regiões e diversidades e com um objetivo comum.

Outro obstáculo são as próprias instabilidades políticas que a gente vem vivendo. O Programa nasceu numa época já de mudança política, de alternância, com objetivos distintos, mas isso não é só peculiar a esta época. Esta é uma época muito específica, mas a gente já viveu várias épocas específicas no Brasil...isso é um obstáculo: você manter um programa funcionando a todo o momento, sem grandes 


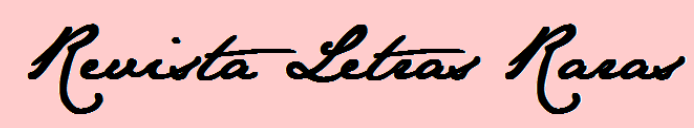

ISSN: 2317-2347 - v.6, n.1 (2017)

alterações, exige bastante da equipe, bastante articulação, paciência, investimento pessoal de todos os envolvidos e resiliência. Mas, é possível de novo desde que todo mundo esteja muito imbuído do que está fazendo, esteja muito ciente de que o que nós estamos fazendo é o certo para as instituições e para o país.

Eu poderia citar um último obstáculo que eu acho que com o tempo ele vai ser resolvido que é a própria resistência da área de Línguas Estrangeiras, Linguística Aplicada, de ainda não estar totalmente consciente daquilo que o programa IsF pode fazer. É um programa que exige muito trabalho, muita dedicação, muito compromisso de muitas pessoas. $\mathrm{Na}$ área, não acreditam que seja um programa de longa duração, por conta de ser um programa de governo, mantido pelo governo, que isso pode em algum momento acabar, e isso acaba colocando em descrédito também algumas ideias que não se alinham com o Programa, dizendo que o Programa é um Programa que visa à aplicação de questões mais comerciais e questões ideológicas envolvidas, mas eu acho que no fundo, se o Programa perdurar e realmente modificar a formação dos nossos professores e valorizá-los da forma como eles devem ser valorizados, eu acredito que ao longo do tempo as pessoas vão percebendo que isso não vem substituir nada e nem vem substituir outros programas de igual valor, ou, às vezes, com muito mais valor. A importância do programa está em justamente dar possibilidade de abrir outras frentes de trabalho para um grupo de profissionais que precisa atender as necessidades que agora as universidades vêm apresentando.

4. Então, pode-se dizer que o IsF é um Programa de políticas linguísticas que tem avançado, mas, depende de questões de política Nacional mais amplas?

Sim, todo programa que se estabelece dentro de um apoio governamental de fomento governamental, depende sim de uma política nacional mais ampla. O IsF nasceu nessa perspectiva de um Programa de grande porte como foi o Ciências sem Fronteiras, que mostrou a necessidade do País em se investir em línguas... mostrou a importância das LE nesse processo de internacionalização e, com isso, nós conseguimos convencer, não só aos nossos colegas, mas também, e principalmente, aos gestores das universidades, da importância dessa área, como nós temos que 


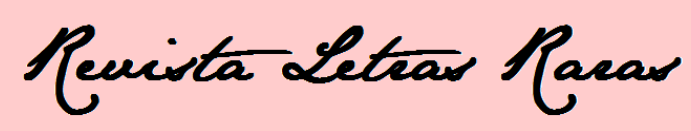

ISSN: 2317-2347 - v.6, n.1 (2017)

investir nessa área. Então, mais do que uma política governamental, isso tem que ser uma política institucional e se a gente articular bem toda essa estrutura, principalmente na rede de especialistas que a gente está formando, isso tem que ser mais perene. Eu acho que o IsF promoveu um grande avanço que é poder incluir essa pauta para as universidades como uma discussão dos grupos gestores, como os reitores, os pró-gestores, das relações internacionais, envolvendo toda a comunidade da gestão para demonstrar que a comunicação é a chave do negócio. Se a gente sabe uma LE, a gente se comunica melhor, a gente pode divulgar melhor nossas pesquisas, a gente pode divulgar melhor nossos trabalhos e o Brasil tem trabalhos excelentes que são pouquíssimos divulgados justamente porque tem esse empecilho da língua.

E uma questão também que a gente tem que lembrar é que nessa articulação nacional a gente depende muito do apoio desses gestores como, por exemplo, órgãos ou associações como ANDIFES que é a associação dos reitores, dos dirigentes das Universidades Federais da ABRUEM, da ABRUC. Quer dizer, essas associações de gestores estando conscientes e apoiando o Programa, será crucial e fundamental para que essa articulação não fique só por conta de um governo, mas que fique mais como uma política de Estado que é necessário e primordial para o avanço das instituições de ensino superior brasileiro.

5. Nesse contexto, (relativo à questão 4), levando em conta a importância do Programa, quando trazemos para a atual realidade política do Brasil, há razões para se preocupar com o futuro do Programa?

Bom, se a gente for olhar, há razões para a gente se preocupar sempre. Nada é garantido, nada é definitivo e as coisas mudam. A gente tem que estar sempre disponível e em condições para se adequar às mudanças. O Brasil vem mudando há muito tempo, algumas horas ele está melhor economicamente e outras pior e a gente sabe disso e isso acontece não só aqui no Brasil, mas em outros lugares, a política internacional também está passando por uma série de mudanças e como nós temos 15 (quinze) parceiros no programa, 9 (nove) países, obviamente a gente articula com vários deles e percebe que também há instabilidade em vários deles. Então, a gente 


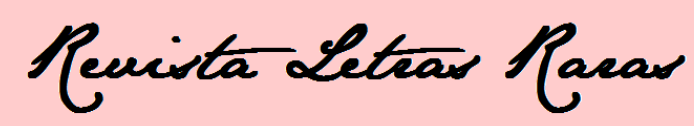

ISSN: 2317-2347 - v.6, n.1 (2017)

precisa estar sempre disposto a se adequar àquilo que aparece e a sempre investir no melhor que for para o Brasil. Mas, mais do que tudo, a gente tem sempre que pensar porque que a gente está fazendo isso [?], se nós estamos fazendo isso para o aluno, em beneficio do aluno da comunidade acadêmica, das instituições e da educação de uma forma geral. Então, se a gente tiver isso como meta, a gente consegue se adequar a qualquer mudança que aparecer.

6. Denise, no ano passado você recebeu um prêmio internacional importantíssimo para o Programa e como consequência, para nós, profissionais de línguas no Brasil, fale-nos um pouco desse prêmio e do orgulho de ver o Brasil recebendo um prêmio desse porte.

Sim! O prêmio do qual você está mencionando ele se chama Distinguished Humphrey Leadership Award. Foi uma primeira edição de um prêmio que normalmente é dado e que pertence a um programa de bolsas nos Estados Unidos chamado Hubert H. Humphrey Fellowship que é um Programa que já existe desde 1978, já deu bolsas para mais de 5.600 profissionais no mundo. Então, é um programa de fellowship bem específico de um ano que é dado para profissionais do mundo inteiro, que no início da carreira acabam se candidatando para esta bolsa, para articular com profissionais de vários países em universidades especificas dos Estados Unidos.

É um programa muito interessante, promovido pelo departamento de Estado nos Estados Unidos e em uma primeira edição, após todos esses anos, eles resolveram fazer um programa para Senior Professionals. Então, para profissionais com mais experiência, que atuassem em políticas públicas. A equipe do Programa fez um levantamento em diferentes países e solicitaram indicação de programas de políticas públicas que tivessem tido algum impacto mais estruturante em seu país; e, o Idiomas sem Fronteiras foi indicado, no ano passado, acho que foi em maio/junho do ano passado, e em agosto eu tive o resultado, a feliz notícia de que o IsF tinha sido indicado e finalmente escolhido como um dos 10 programas no mundo que tiveram impacto na sua comunidade.

Dos dez programas, o IsF é o único programa na área da educação e o único programa das Américas... nós ficamos muito satisfeitos, eu fui receber esse Prêmio, no 


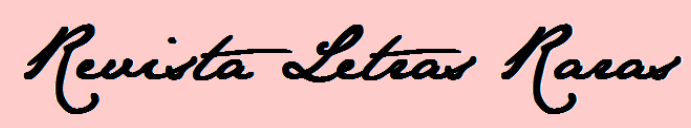

ISSN: 2317-2347 - v.6, n.1 (2017)

ano passado e ele consistia especificamente de duas partes, um curso na Escola de Governo da Universidade de Harvard e foi ofertado o curso sobre Leadership, e foi um curso que envolveu, além dos premiados, líderes de vários países, mais de oitenta países estavam representados lá, então os dez condecorados pelo prêmio fizeram parte deste grupo. Ficamos uma semana tendo um treinamento e uma capacitação com todos os pesquisadores ali envolvidos com Leadership e foi tremendamente importante fazer este curso e trazer a perspectiva do que eles ensinaram pra dentro do programa. Em seguida, na semana seguinte, houve um processo de Job shadowing que consistia justamente de eu ficar alocada em uma determinada organização em Washington, fazendo contatos com vários parceiros que poderiam nos auxiliar no processo de gestão do programa e que fossem do meu interesse. Então, fiz várias visitas locais, várias reuniões e nessas reuniões pude articular muitas coisas e uma delas foi o Letras sem Fronteiras, que é justamente a parceria que nós estamos agora para um piloto do Programa com a embaixada americana American Association of State Colleges and Universities nos Estados Unidos em que nós vamos fazer uma interlocução entre os professores do IsF, indicados pelos seus coordenadores então um piloto com cinco universidades brasileiras e cinco universidades americanas, pra fazer um intercâmbio cultural-acadêmico entre esses professores. Acho que vai ser uma experiência muito gratificante porque esses meninos vão poder ir para o exterior, ter a sua primeira experiência acadêmica em universidades americanas e vão poder divulgar o português do Brasil e o nosso teste de proficiência que é o Celpe-Bras.

Uma das coisas que fiz assim que eu retornei do Programa, eu repliquei o conteúdo que me foi ensinado lá em Harvard pra todos os coordenadores gerais do IsF, justamente pra compartilhar e tornar esses conhecimentos pra que eles pudessem aplicar também na sua gestão local.

\section{O que gostaria de acrescentar?}

O que muitas pessoas perguntam a mim é porque este programa está dando certo. E eu digo o seguinte: fazendo uma avaliação de tudo o que a agente vem 


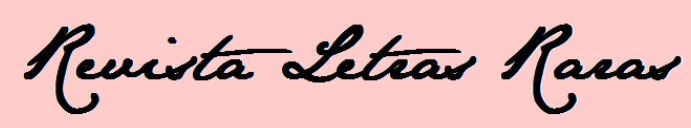

ISSN: 2317-2347 - v.6, n.1 (2017)

experimentando na universidade, a gente consegue fazer mais no IsF, como em qualquer outro Programa, primeiro porque nós temos o apoio institucional; segundo, porque nós somos valorizados internamente; terceiro, porque nós somos uma rede de especialistas. A gente tem uma sensação de pertencimento de que estamos fazendo isso coletivamente, que não é só um esforço local, é um esforço nacional. Todo mundo compartilha angústias, compartilha seus desafios e também compartilha soluções. Então, nós somos uma rede não mais só de colegas, mas, de amigos, de pessoas que querem, realmente, fazer algo, juntas. Então, isso não só para os coordenadores, como também para os professores. A gente percebe isso, na fala dos professores, como eles se sentem pertencendo a algo muito maior...maior do que simplesmente ter um diploma. Estou modificando uma realidade... sinto que a gente está trazendo de volta aquela sensação gostosa de ver o brilho nos olhos dos alunos quando eles dizem: "Eu vou ser professor"; "-Eu sou um professor" e "-Eu quero ser um professor".

Denise Martins de Abreu-e-Lima, Presidente do Programa Idiomas sem Fronteiras, obrigada por sua entrevista. Como profissionais das Letras, o nosso desejo é que o Programa se consolide cada vez mais e parabéns pelo brilhante trabalho desenvolvido no IsF.

\footnotetext{
' Entrevista concedida à Josilene Pinheiro-Mariz, que agradece à Denise Martins de Abreu-e-Lima e, igualmente, agradece à Maria Rennally Soares da Silva, Bianca Souza da Silva, Déborah Alves Miranda e Diana Barbosa de Freitas pela ajuda na transcrição dos áudios desta entrevista.
} 